\title{
Evolutionary Diversification of the Lizard Genus Bassiana (Scincidae) across Southern Australia
}

\author{
Sylvain Dubey*, Richard Shine \\ School of Biological Sciences, University of Sydney, Sydney, New South Wales, Australia
}

\begin{abstract}
Background: Relatively recent (Plio-Pleistocene) climatic variations had strong impacts on the fauna and flora of temperatezone North America and Europe; genetic analyses suggest that many lineages were restricted to unglaciated refuges during this time, and have expanded their ranges since then. Temperate-zone Australia experienced less severe glaciation, suggesting that patterns of genetic structure among species may reflect older (aridity-driven) divergence events rather than Plio-Pleistocene (thermally-mediated) divergences. The lizard genus Bassiana (Squamata, Scincidae) contains three species that occur across a wide area of southern Australia (including Tasmania), rendering them ideally-suited to studies on the impact of past climatic fluctuations.
\end{abstract}

Methodology/Principal Findings: We performed molecular phylogenetic and dating analyses using two partial mitochondrial genes (ND2 and ND4) of 97 samples of Bassiana spp. Our results reveal a pattern of diversification beginning in the Middle Miocene, with intraspecific diversification arising from 5.7 to 1.7 million years ago in the Upper Miocene-Lower Pleistocene.

Conclusions/Significance: In contrast to the temperate-zone Northern Hemisphere biota, patterns of evolutionary diversification within southern Australian taxa appear to reflect geologically ancient events, mostly relating to east-west discontinuities imposed by aridity rather than (as is the case in Europe and North America) relatively recent recolonisation of northern regions from unglaciated refugia to the south.

Citation: Dubey S, Shine R (2010) Evolutionary Diversification of the Lizard Genus Bassiana (Scincidae) across Southern Australia. PLoS ONE 5(9): e12982. doi:10.1371/journal.pone.0012982

Editor: M. Thomas P. Gilbert, Natural History Museum of Denmark, Denmark

Received July 1, 2010; Accepted September 2, 2010; Published September 24, 2010

Copyright: (c) 2010 Dubey, Shine. This is an open-access article distributed under the terms of the Creative Commons Attribution License, which permits unrestricted use, distribution, and reproduction in any medium, provided the original author and source are credited.

Funding: The work was funded by the Australian Research Council. The funders had no role in study design, data collection and analysis, decision to publish, or preparation of the manuscript.

Competing Interests: The authors have declared that no competing interests exist.

*E-mail: sylvain.dubey@bio.usyd.edu.au

\section{Introduction}

The geographic distribution of genetic diversity within a biological lineage can tell us a great deal about the processes that have affected those organisms over evolutionary time. For example, major genetic discontinuities can reveal places where barriers to dispersal occurred, often reflecting areas unsuitable for the species' persistence at some time in the past [1]. Information on the timing of such events, also obtainable from genetic data, can help to identify the nature of processes (e.g., climatic variation, sea-level fluctuation, volcanic activity) that created barriers to gene flow.

Palynological data suggest that the impact of climatic variation on the vegetation was weaker in the Southern Hemisphere than in the North, because large ice sheets were rare and full glacial conditions did not persist during interglacial periods; thus, forested or partially forested areas existed in mesic habitats of southeastern and southwestern Australia even during the Last Glacial Maximum [2]. Nonetheless, the distributions of particular vegetation types presumably expanded and contracted during the glacial fluctuations of the Upper Pliocene and Pleistocene $[3,4]$. Also, extreme arid conditions rendered large regions of inland Australia unsuitable for vegetation, leading to the formation of active sand and clay dune systems. Clearly, these modifications would have had a substantial impact on the distributions of all types of fauna in arid temperate areas [5]

Although the impacts of Pleistocene climatic variations on the fauna of southern Australia remain unclear, the past climatic history of southern Australia is relatively well-understood. From the Lower-Middle Miocene (23 mya [million years ago]), Australia was warm and wet, even in areas now covered by desert [6]. Further south in Antarctica, ice was absent until 14 mya [7]. In the Upper Miocene, the disappearance of these stable, warm, wet conditions caused a contraction of rainforest, an expansion of xerophyllous plant species such as Eucalyptus and Casuarinaceae, and the retreat of the southern marine basin (e.g., the Murray and Gippsland basins in southeastern Australia: [5,8]. Although warm and wet conditions (and thus, rainforest) returned in the Lower Pliocene (5-3 mya), climatic fluctuations (cool-dry to warm-wet) and a global cooling-drying trend through the Pliocene favoured the expansion of woodlands, sclerophyllous forest and grasslands (but still wetter than today; [5,8-12]). The beginning of the Pleistocene marked a transition to cold and dry conditions, and the lower sea level (to more than $120 \mathrm{~m}$ lower; [13,14]) periodically connected continental islands to the mainland (e.g. Tasmania; [15]). Pleistocene climatic fluctuations reached a maximum amplitude over the last $0.4 \mathrm{Myr}$, with temperatures 10 to $5^{\circ} \mathrm{C}$ lower during the last Glacial Maximum 21,000 years ago than 
present-day conditions and/or fully arid conditions (LGM; $[5,8,16])$. However, glaciation was limited to Tasmania and the southeastern highlands [8].

These climatic fluctuations were likely to exert stronger effects on the distribution and abundance of some species than others. For example, terrestrial ectotherms (such as reptiles) depend upon ambient thermal heterogeneity for behavioural thermoregulation, and hence are sensitive to local climatic conditions (e.g. $[17,18])$. Consequently, reptiles provide excellent model systems with which to study the impact of past climatic variations, because the genetic signatures of past events are likely to be discernable in these taxa. In the present study, we performed molecular phylogenetic and dating analyses on a widespread genus of lizards (Bassiana, Scincidae, Squamata) from southern Australia (Fig. 1), to document patterns of genetic diversification within this group and to clarify potential impacts of past climatic variations and geographic barriers on gene flow in this taxon.

\section{Results}

\section{Phylogenetics analyses}

The 97 samples showed 92 different haplotypes of $1412 \mathrm{bp}$ (combined dataset; GenBank accession numbers GU811882GU812071), containing 414 variable sites, of which 353 were parsimony-informative (excluding outgroups). Because trees from the BA, ML and MP analyses showed very similar relationships, only the ML tree is shown (with ML, MP, and BA support values: Fig. 2).

The genus Bassiana, as well as the three species within it, formed monophyletic units (support of 100, 100 and 1.0 for MP, ML, and BA analyses except for Bassiana platynota where BA analyses provided only poorly support for its monophyly; Fig. 2). However, the phylogenetic relationships between the three species remain unclear.

Major phylogenetic divisions were evident within each of the three Bassiana species. Two well-supported lineages corresponding to different geographic locations were found within B. trilineata (I: Western Australia; II: South Australia, Figs. 2 and 3), seven geographically localised lineages within $B$. duperreyi (IX: Kangaroo Island, VIII: western SA, V: eastern SA, X: southern VIC, XII:
TAS, XIII: northern VIC and ACT, XI: NSW), and four within B. platynota (IV: northern NSW, V: Sydney area, VI: Kanangra Boyd and Morton NP; III: southern NSW).

The three species are well-separated genetically. Mean K2P genetic distances between species were $11.1 \%$ for duperreyi-platynota, $12.3 \%$ for duperreyi-trilineata, and $12.8 \%$ for platynota-trilineata. The genetic distance between the two lineages of $B$. trilineata was $2.9 \%$, whereas the genetic distances between the lineages of $B$. duperreyi varied from 2.3 (XII-XIII) to $5.3 \%$ (VIII-XII), and between the lineages of $B$. platynota from 3.3 (V-VI) to $4.7 \%$ (III-IV). Genetic distances within lineages varied from 0.3 (IV) to $1.1 \%$ (XII) in $B$. duperreyi, from 0.8 (VI) to $3.1 \%$ (IV; excluding lineage III represented by one sample) in $B$. platynota, and from 0.5 (II) to $0.8 \%$ (I) in B. trilineata.

\section{Dating analyses}

The phylogenetic split between the three Bassiana species occurred in the Miocene (BA: 13.4 Myr, 95\% HPD: 11.0-17.2; PL: 14.7, 95\% HPD 13.2-19.3; 1.3\%: $16.2 \mathrm{Myr}$, 95\% HPD: 12.2-16.7; 2.3\%: 9.7 Myr, 95\% HPD: 7.9-10.8; datings of divergence points are given in the same order below; see Fig. 3 for more details). Within $B$. duperreyi, the estimates dates of divergence between the major lineages began in the Upper Miocene and/or Upper Pliocene (3.9 Myr, 95\% HPD: 3.6-5.9; 4.8, 95\% HPD 4.2-6.6; 5.7 Myr, 95\% HPD: 4.7-6.6; 3.3 Myr, 95\% HPD: 2.63.7), depending on the calibration method. Within B. platynota, the splits between the major lineages began in the Lower and Upper Pliocene (3.2 Myr, 95\% HPD: 3.2-5.3; 4.3, 95\% HPD 3.7-5.9; 4.4 Myr, 95\% HPD: 4.1-5.9; 2.3 Myr, 95\% HPD: 2.3-3.3), and within $B$. trilineata from the Lower Pliocene to the Lower Pleistocene between the two main lineages (3.3 Myr, 95\% HPD: 1.9-3.8; 3.7, 95\% HPD 2.3-4.3; 3.0 Myr, 95\% HPD: 2.54.3 ; 1.7 Myr, 95\% HPD: 1.4-2.4), again depending on the calibration method. Finally, diversification within each of these intraspecific lineages occurred from the Upper Miocene in lineage VIII of $B$. duperreyi (based on a divergence rate of $1.3 \%$ $\mathrm{Myr}^{-1}$; 2.0 Myr 95\% HPD: 1.0-2.1) to the Middle Pleistocene in lineage III of $B$. duperreyi (based on a divergence rate of $2.3 \%$ $\mathrm{Myr}^{-1}$; 0.2 Myr 95\% HPD: 0.2-0.4; see Fig. 3 for more details about the dating results).

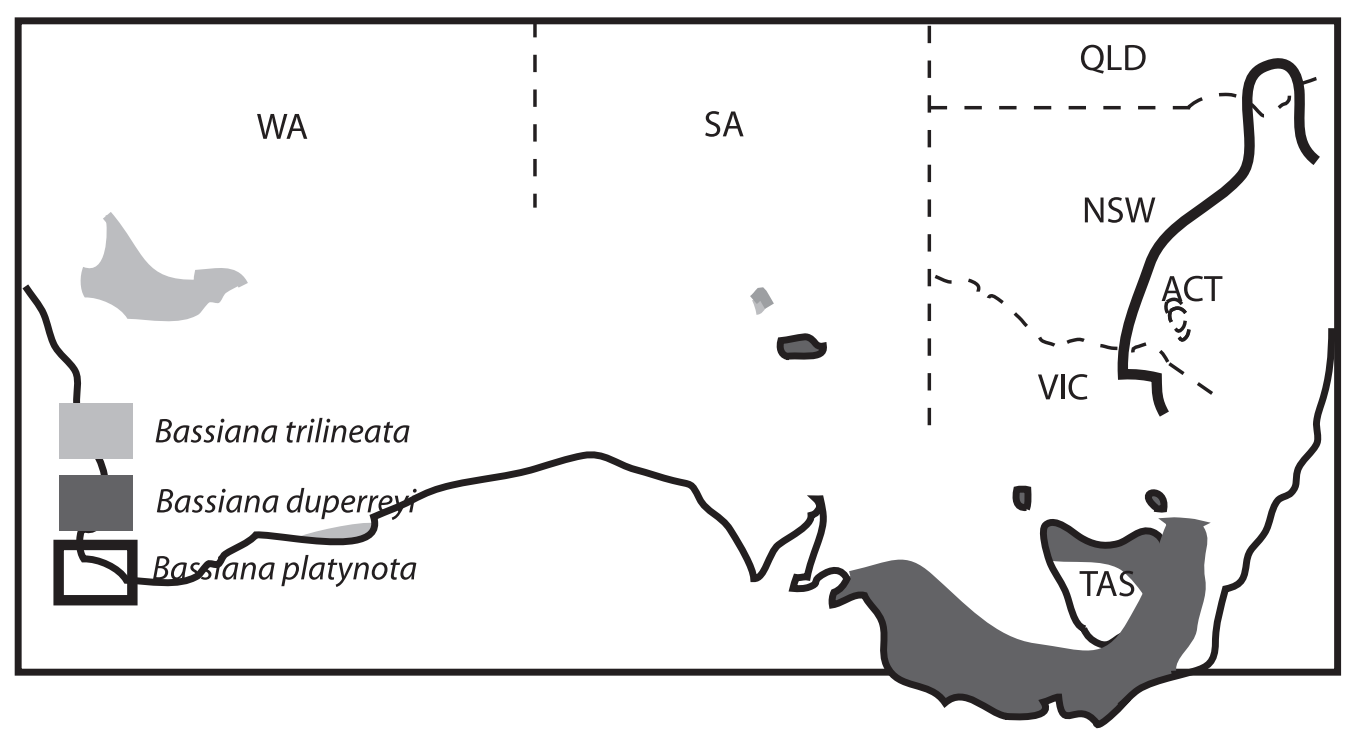

Figure 1. Distribution of Bassiana species in southern Australia. doi:10.1371/journal.pone.0012982.g001 


\begin{tabular}{|c|}
\hline \multicolumn{1}{|c|}{ MP } \\
Support: $\mathrm{ML}$ \\
$\mathrm{BA}$ \\
$\mathrm{BA}$ \\
$\mathrm{PL}$ \\
Dating (Myr): \\
$1.3 \% / \mathrm{Myr}$ \\
$2.3 \% / \mathrm{Myr}$ \\
Miocene: $20.3-5.3 \mathrm{Myr}$ \\
Pliocene: $5.3-1.8 \mathrm{Myr}$ \\
Pleistocene: $1.8-0.012 \mathrm{Myr}$ \\
\hline
\end{tabular}

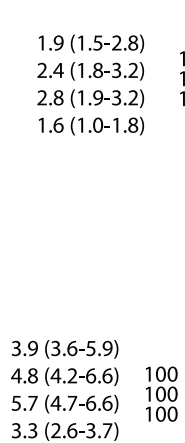

91
95
100
98

21, T064

64, ABTC23606

$\begin{aligned} & 100 \\ & 100\end{aligned} 27$, ABTC57498

$\begin{array}{lll}3.3(2.6-3.7) & \\ 72 & 24, \text { CF2 } \\ 89 & 27, \text { ABTC57507 } \\ 89 & 24, \text { CF4 } \\ 89 & 25, \text { ABTC11245 }\end{array}$

$\begin{array}{lll}3.3(2.6-3.7) & \\ 72 & 24, \text { CF2 } \\ 89 & 27, \text { ABTC57507 } \\ 89 & 24, \text { CF4 } \\ 89 & 25, \text { ABTC11245 }\end{array}$

$3.5(3.2-5.3)$
$4.3(3.8-6.0)$
$4.7(4.1-5.9)$
$3.2(2.3-3.3)$

$2.0(1.5-2.9)$
$2.5(1.8-3.2)$
$2.6(1.9-3.2)$
$1.5(1.1-1.8)$

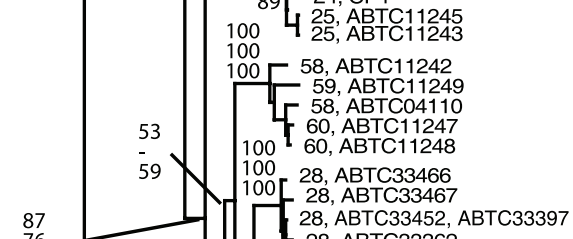

$98-\square\left[\begin{array}{l}28, \mathrm{ABTC} 33362 \\ 28 \\ 28, \mathrm{ABTC} 33500 \\ 28, \mathrm{ABTC} 33431\end{array}\right.$

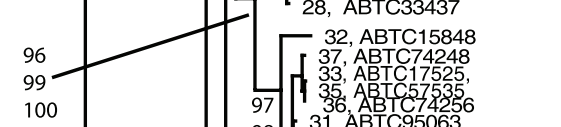

100

41, ABC58806

$13.4(11.0-17.2)$

$14.7(13.2-19.3) \quad 100$

$16.2(12.2-16.7) \quad 100$ $9.7(7.9-10.8)$

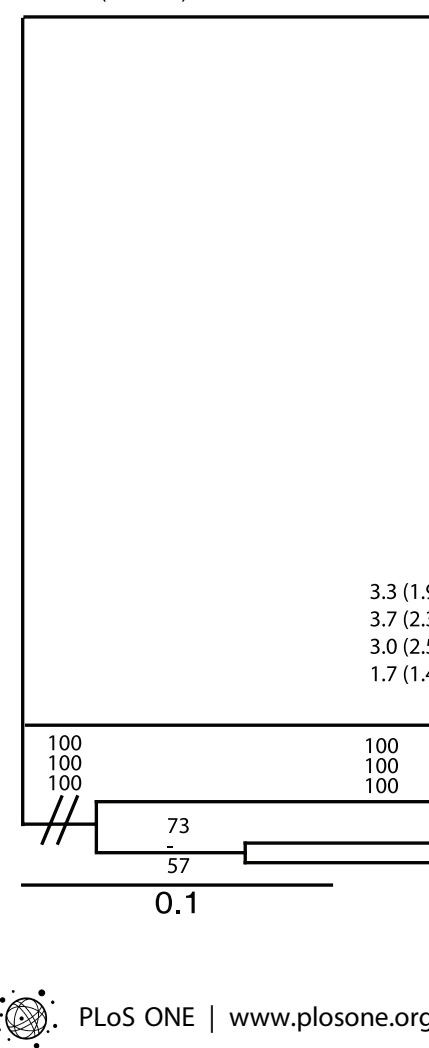

10095
100
100

100

95 62, ABTC23543

100 บ 64, ABTC23610

64, ABTC23592

64, ABTC23588

$100-\left[\begin{array}{ll}24, \mathrm{CF} 3 \\ 24, \mathrm{TO5} 5\end{array}\right.$

23, T055

난, 24 CF1

28, АВTC 33437

$31, \mathrm{ABTC} 74256$

40, ABTC68913

72 30, ABTC94916

91 . 29, ABTC33274

82 - 38, ABTC 74406

- 39, АВTC 33275

39, ABTC 33275
34, ABTC74477

[56, АBTC 37423

51 , ABTC 14265

43, ABTC 35073

44, ABTC 38069

$\begin{array}{ll}44, \text { ABTC38069 } & 1.0(0.7-1.4) \\ 42, \text { ABTC } 34348 & 1.0(0.8-1.5)\end{array}$

43, ABTC 37399

49, ABTC 36241

- 50, ABTC14283

$1.4(0.8-1.9)$

$1.1(0.9-2.1)$

$2.0(1.0-2.1)$

$1.2(0.6-1.2)$

$1.1(0.9-1.9)$

$1.4(1.1-2.1)$

$1.5(1.2-2.14)$

$1.1(0.7-1.2)$

$0.9(0.6-1.4)$

$0.7(0.7-1.6)$

$1.2(0.7-1.6)$

$0.7(0.4-0.9)$

$0.8(0.7-1.6)$ $1.4(0.8-1.8)$ $1.5(0.9-1.8)$

$1.0(0.5-1.0)$

$0.3(0.2-0.7)$

$0.6(0.3-0.8)$ $0.4(0.3-0.8)$

$0.2(0.2-0.4)$

$1.0(0.7-1.6)$ $1.2(0.8-1.8)$ $1.4(0.9-1.8)$

$0.8(0.5-1.0)$ $1.0(0.8-1.5)$ $1.1(0.8-1.5)$

$0.7(0.5-0.9)$

eastern SA, VII

100 53, ABTC54773

51, ABTC53794

004 46, ABT53794

4 48, ABTC57701

100

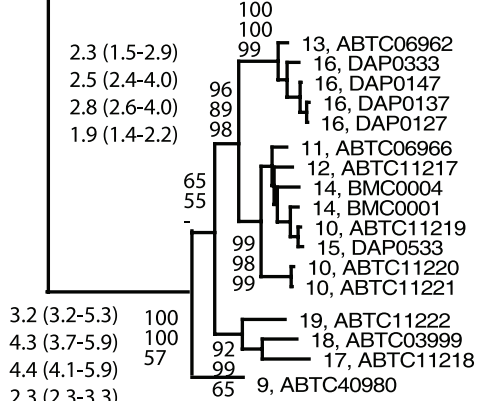

$0.8(0.5-1.3)$

$1.1(0.6-1.5)$

$1.0(0.6-1.5)$

$0.5(0.4-0.9)$

$1.2(1.1-2.1)$

$2.0(1.3-2.4)$

$1.4(1.4-2.4)$

$1.2(0.8-1.4)$

$2.6(1.9-3.5)$

$2.6(2.1-3.9)$

$2.7(2.3-3.9)$

$1.4(1.3-2.2)$

ACT

northern Victoria, XIII

Tasmania

Flinders IsI, XII

NSW, XI

southern VIC, X

Kangaroo IsI (SA), IX

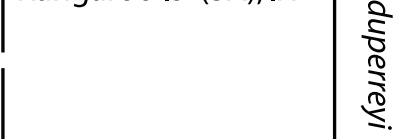

western SA, VIII

Kanangra Boyd NP

Morton NP (NSW), V

"Sydney area"

(NSW), V

northern NSW, IV

I southern NSW, III

$0.4(0.1-0.6)$

$0.8(0.4-1.2)$

$0.9(0.4-1.2)$

$0.3(0.2-0.7)$

$0.9(0.5-1.3)$

$1.2(0.6-1.5)$

$0.9(0.7-1.5)$

$0.5(0.4-0.8)$

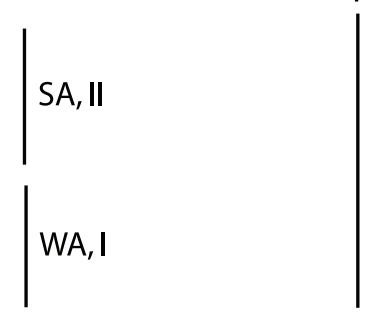

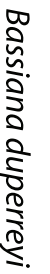


Figure 2. Phylogeny of the 1412 bp ND2+ND4 fragment of the scincid lizard genus Bassiana in southern Australia analysed using a maximum likelihood (ML) procedure and the $\mathbf{T r N +}+\mathbf{G}$ model of substitution. Support values shown for the major clades only for maximum parsimony (MP), maximum likelihood (ML), and Bayesian (BA) analyses; and dating of the major splits in Myr from the BEAST analyses, with the secondary calibrations points from Albert et al. (2009) respectively BA-based and PL-based, and the divergence rates of respectively $1.3 \% / \mathrm{Myr}$ and 2.3\%/Myr. Codes are as in Table S1.

doi:10.1371/journal.pone.0012982.g002

These data suggest that five distinct lineages of $B$. duperreyi occur in mainland Australia, plus one in Tasmania and Flinders Island, and one in Kangaroo Island (SA). An early split (Upper MioceneUpper Pliocene) occurred between lineages in south-eastern Australia (XII: TAS; XIII: ACT, Northern VIC, bioregion of South Eastern Highland and Australian Alps) and the other (northern and western) conspecifics, followed by a second split between eastern (XI: NSW, South Eastern Highland) and western populations (IX to X: VIC and SA) in the Upper-Lower Pliocene. The lineages of $B$. duperreyi from SA and southern VIC occur in different bioregions, respectively in the Murray Darling Depression and Kanmantoo region (VIII), Naracoorte Coastal Plain (VII), Victorian Volcanic Plain and South East Coastal Plain (X; [19]), and appear to have diversified in the Upper Pliocene-Lower Pleistocene.

\section{Discussion}

Our analyses reveal strong biogeographic structure within Bassiana in southern Australia, with an initial diversification of the genus occurring in the Miocene (16.2-9.7 mya; fig. 2), at about the same time that climatic conditions in southern Australia became less stable and more arid [5]. Diversification within each of the three Bassiana species also began long ago, probably from the Upper Miocene (5.7 Myr) to the Lower Pleistocene (1.6 Myr). Most of this intraspecific diversification occurred during the Pliocene (Fig. 2), a period marked by a global cooling and drying trend [9-11]. Plausibly, those climatic changes rendered many parts of Australia unsuitable for these lizards, splitting formerly continuous populations into at least 13 major genetic lineages, each in a different geographic region.

Although mainland Australia and Tasmania currently are separated by Bass Strait (average depth of $60 \mathrm{~m}$ : [20]), variations in sea level created land bridges (and thus, opportunities for terrestrial dispersal of lizards) several times over the last $10 \mathrm{Myr}$. At least two such events occurred during the last $0.5 \mathrm{Myr}$, with sea levels up to $150 \mathrm{~m}$ lower than at present [15]. Similar connections would have occurred between Kangaroo Island and mainland (currently separated by the Backstairs Passage with an average depth of $36 \mathrm{~m})$. The split between insular populations of $B$. duperreyi in Tasmania (XII) and Kangaroo Island (IX) and their most closely related mainland populations, during the Upper Pliocene-Lower Pleistocene is in accord with these sea-level-driven dispersal opportunities. Similarly, the current east-west split in $B$. trilineata populations (WA vs SA's Eyre Peninsula) reflects the inhospitable habitats of the arid Nullarbor Plain, and hence a cessation of genetic exchange during the Lower Pliocene and Upper Pleistocene. In $B$. platynota, the same pattern is observed: diversification beginning in the Lower and/or Upper Pliocene and dividing populations into four main lineages, one in the South Eastern Highlands (III), two in the Sydney Basin (South: VI and North: V), and one on the NSW North Coast (IV).

The considerable antiquity of these phylogenetic divergences within Bassiana also is evident from the diversification of haplotypes within intraspecific lineages (except lineage XIII of $B$. duperreyi, represented by only one sample). Many of these divergences appear to date back to the Upper Pliocene through to the Lower and Middle Pleistocene. Any impact of the last
Glacial Maximum (21,000 years ago; [16]) would be apparent in genetic homogeneity over large areas (reflecting recent recolonisation) and/or the elimination of the genetic signatures of more ancient divergence events (because of extirpation of populations over wide areas). Neither of these patterns is apparent, suggesting that these recent climatic fluctuations had no substantial impact on present genetic diversity within lineages. Conditions over most of southern Australia appear to have remained suitable for population persistence, allowing endemic lineages of these lizards to persist.

In summary, lizards of the genus Bassiana have evolved in southern Australia over a period of at least 10 million years (interspecific divergences), and most of the major intraspecific phylogenetic divergences among this lineage occurred at least 5.7 million years ago to 1.7 million years ago. Climatic fluctuations during the Upper Pleistocene (including the Last Glacial Maximum) do not appear to have substantially affected the extent of areas within lizards could persist, with the result that the genetic signature of ancient divergence events (between and within lineages) remains clearly expressed in modern-day populations in the form of strong geographically-associated genetic structure.

These conclusions accord well with the results of phylogenetic analyses of other reptile and amphibian lineages within southern Australia. Some widespread taxa show little geographic genetic structure, presumably reflecting recolonisation events after older populations were wiped out by relatively recent (Pleistocene) sealevel fluctuations (tigersnake Notechis scutatus; [21]). More commonly, however, reptile and amphibian lineages in southern Australia are highly structured genetically, and reflect the results of ancient diversifications. For example, geckos of the Diplodactylus vittatus complex began to diverge about 20-25 mya, in the Lower Miocene and Pliocene [22]). Unsurprisingly, different lineages have reacted to historical climatic fluctuations in different ways. For example, a deep divergence between mainland Australia and Tasmania is evident in some lineages (e.g., the skinks Lerista bougainvilli [23] and Bassiana duperreyi [current study], and the froglet Crinia signifera [24]) whereas animals in the two areas are similar genetically in other taxa (e.g., the frogs Limnodynastes peronii and L. tasmaniensis [25], the skink Egernia whitii [26], and the snake Notechis scutatus [21]). Plausibly, such interspecific differences in spatial genetic structure reflect interspecific differences in factors such as habitat requirements, past distributions and dispersal capacities.

Within south and southeastern Australia complex patterns emerge. These include the presence of multiple lineages, as in Bassiana species (duperreyi, platynota, and trilineata; this study), Egernia whitii [26], Lerista bougainvilli [23], Diplodactylus [22], and Crinia signifera [24]. The skinks Egernia whitii [26] and Bassiana duperreyi (current study), as well as the frogs Limnodynastes spp [25], and Crinia signifera [24] show a major divergence between western/eastern or southern/northern populations with a geographic limit situated in Victoria-southern NSW. In Egernia whitii and Crinia signifera, the geographic breaks among the lineages are consistent with MiocenePliocene uplift in the Great Dividing Range, as well as elevated sea levels in East Gippsland [24,26]. Schaüble \& Moritz [25] estimated the split between Limnodynastes spp. populations of these two regions to have occurred during the same period. 
Bassiana trilineata Bassiana duperreyi
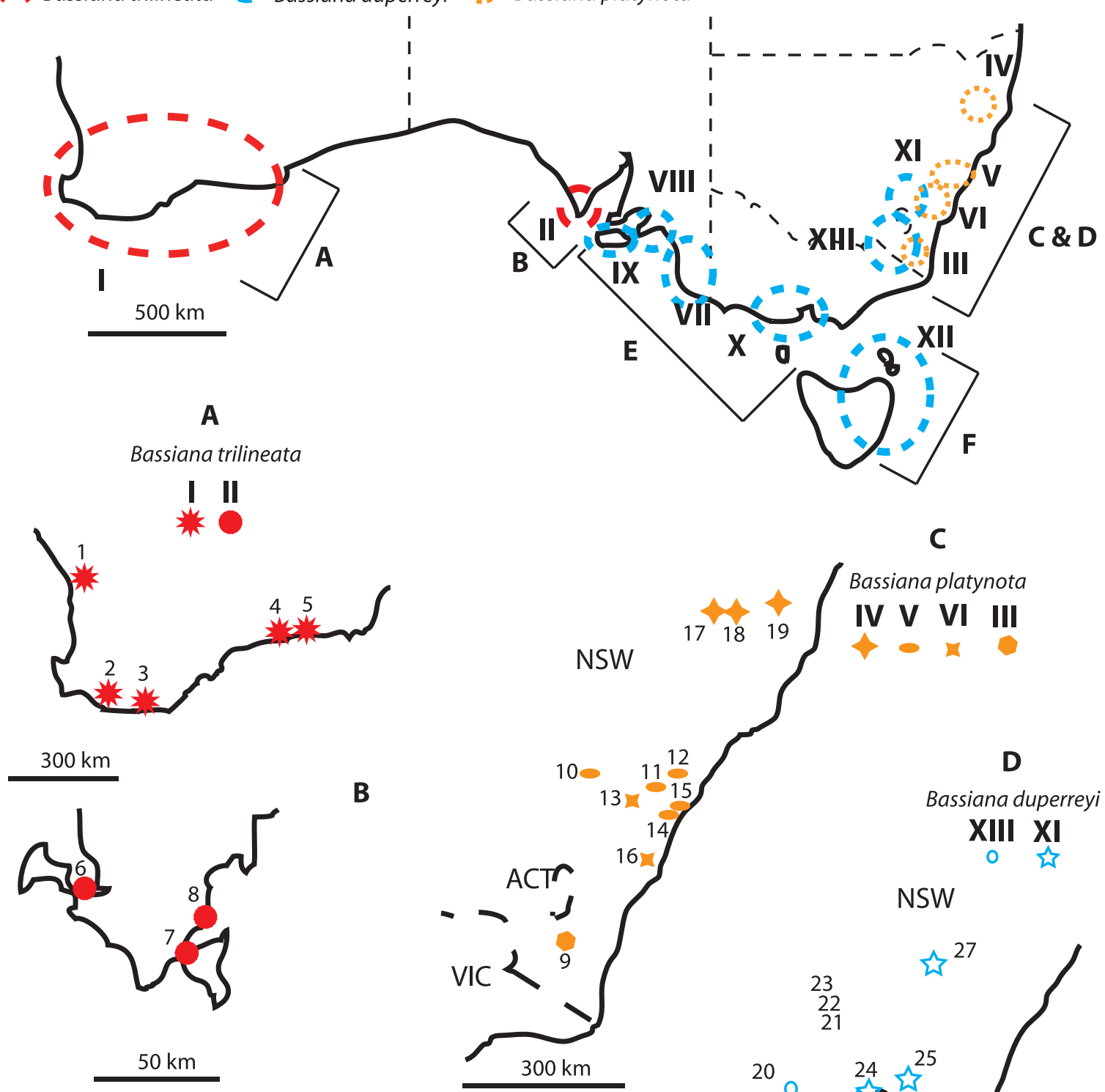

$300 \mathrm{~km}$

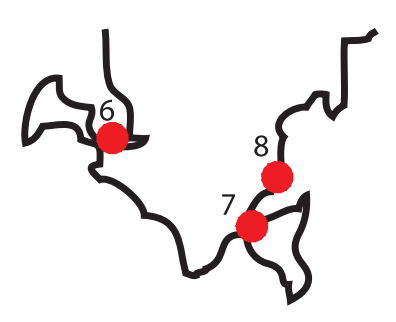

B

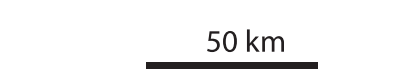

B

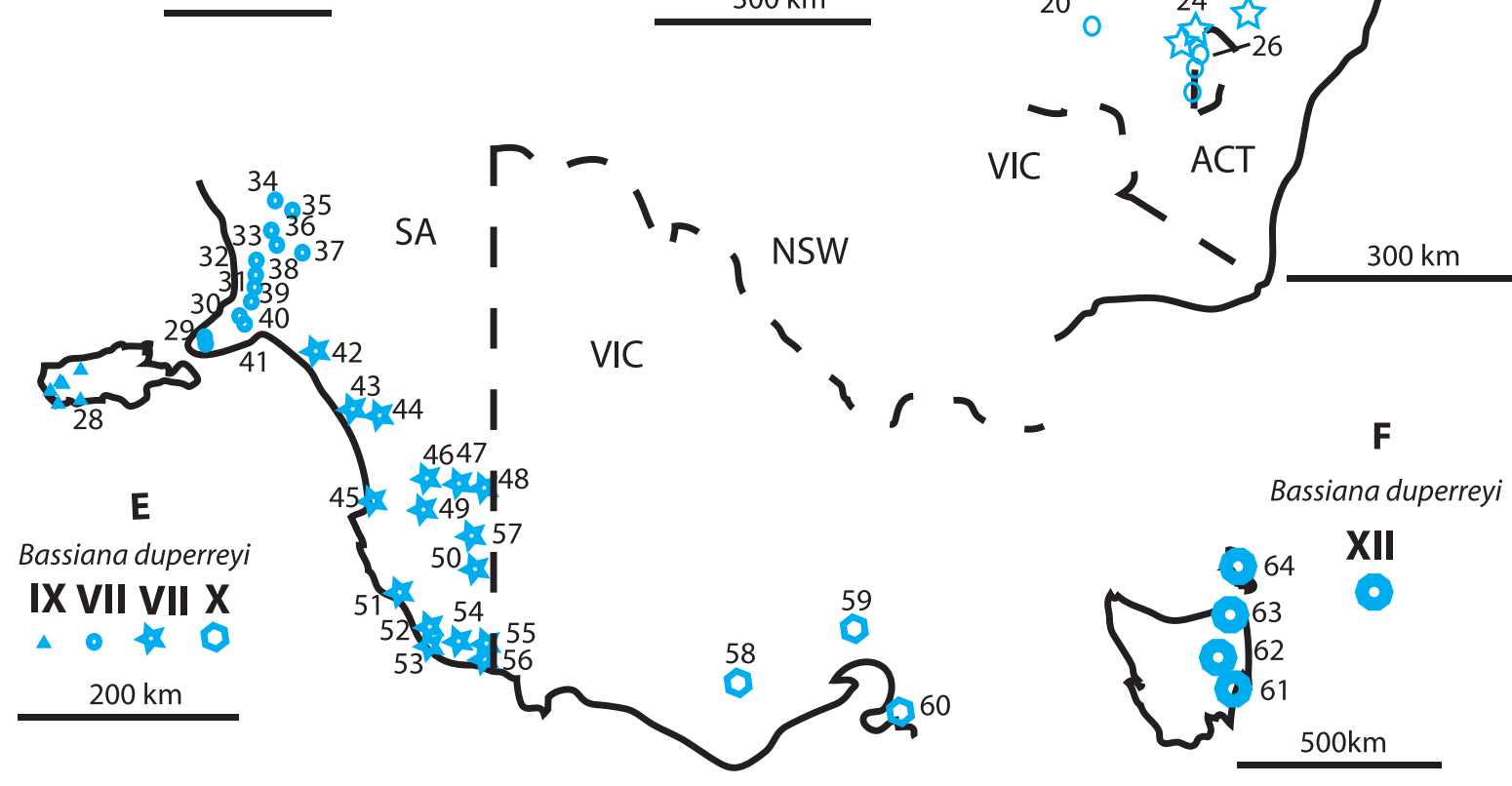

C
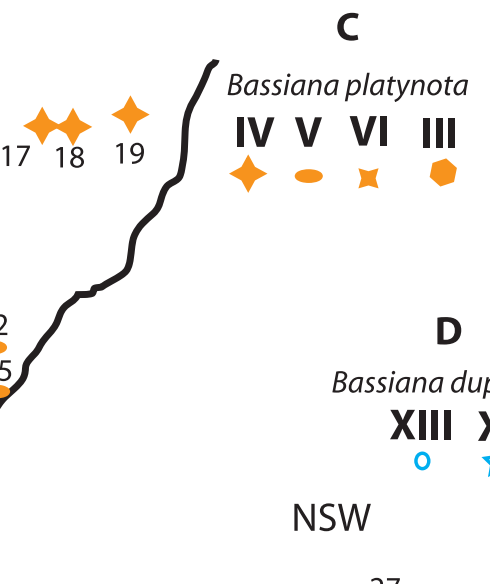

$$
\begin{gathered}
\text { Bassiana duperreyi } \\
\text { XIIII XI }
\end{gathered}
$$

NSW

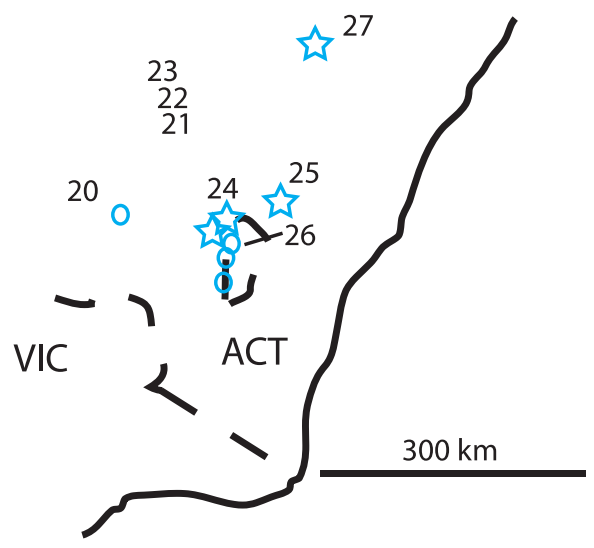


Figure 3. Distribution of Bassiana samples and genetic lineages from the present study (A-B: B. trilineata; C, E, and F: B. duperrey; D: B. platynota). Codes are as in Table S1.

doi:10.1371/journal.pone.0012982.g003

Similarly, in NSW, major breaks occur between southern and northern populations in taxa such as Egernia whitii [26], the Litoria citropa group [27], Oedura lesueurii [28], Tympanocryptis spp [4], Bassiana platynota (current study), Crinia signifera [24], and Limnodynastes spp. [25] with a plausible Miocene and Pliocene diversification in the five latter taxa.

These consistently strong patterns of genetic structure suggest that much of the modern reptile and amphibian fauna of southern Australia bears a strong stamp of divergence events that occurred many million of years ago, and were caused by climatic events that long preceded Pleistocene climatic fluctuations (i.e. in the Miocene and Pliocene). Phylogenetic studies on arid adapted-species from central Australia also suggest a pattern of diversification dating from the mid-Miocene, driven by increasing aridity at that time rather than by thermal fluctuations during the Pleistocene (see [24] for a detailed review). This pattern offers a striking contrast with studies on Northern Hemisphere taxa, where thermal fluctuations (glacial periods) during the Pleistocene eliminated animals from extensive areas, erasing the genetic signature of earlier endemic radiations (e.g. [29-32]). Consistent with these studies, a metaanalysis [33] revealed that species of reptiles and amphibians from temperate-zone areas of the Northern Hemisphere tend to be younger (in term of the age of earliest intraspecific diversification) than are taxa found at similar latitudes in the Southern Hemisphere. This long-retained genetic evidence of ancient aridity-driven phylogenetic divergence within presently wideranging ectotherms in southern Australia thus provides strong support for the hypothesis that Pleistocene climatic fluctuations in southern Australia were not sufficiently intense to eradicate reptiles and amphibians from most areas.

\section{Materials and Methods}

\section{Tissue sampling and DNA extraction}

The genus Bassiana (= Acritoscincus, Eulepis, or Leiolopisma in other taxonomic schemes: e.g., [34-36] comprises three recognised species of diurnal ground-dwelling oviparous skinks, all of medium size [37]. The south-western cool-skink Bassiana trilineata (Gray, 1838) is distributed in Western Australia (WA) and South Australia (SA), the bold-striped cool-skink Bassiana duperreyi (Gray, 1838) in New South Wales (NSW), Victoria (VIC), Tasmania (TAS) and SA (including Kangaroo Island), and the red-throated cool-skink Bassiana platynota (Peters, 1881) in NSW and VIC (Fig. 1).

We analysed a total of 97 samples of Bassiana from Australian museum collections (Museum Victoria, Australian National Wildlife Collection CSIRO, and South Australian Museum) or collected recently in the field. The study was approved by the University of Sydney Animal Care and Ethics Committee (L04/72007/3/4665), and samples were collected in ACT and NSW with the permits LT2009355 and S10826, respectively (see Table S1 for more details). Small tail clips or liver (for samples from museum collections) were used to isolate total cellular DNA, and tissues were placed in $200 \mu \mathrm{L}$ of $5 \%$ Chelex containing $0.2 \mathrm{mg} / \mathrm{mL}$ of proteinase $\mathrm{K}$, incubated overnight at $56^{\circ} \mathrm{C}$, boiled at $100^{\circ} \mathrm{C}$ for $10 \mathrm{~min}$, and centrifuged at 13,300 $\mathrm{g}$ for $10 \mathrm{~min}$. The supernatant, containing purified DNA, was removed and stored at $-20^{\circ} \mathrm{C}$.

\section{DNA amplification}

Double-stranded DNA amplifications of NADH dehydrogenase 4 (ND4) and 2 (ND2) were performed respectively with the primer pairs ND4/LEU [38] and AT4482 (5'caacatgacaaaaattrgcccc3')/ tRNA-ASN (Keogh et al., unpublished; [39]. Amplification conditions included a hot start denaturation of $95^{\circ} \mathrm{C}$ for $3 \mathrm{~min}$, followed by 35 cycles of $95^{\circ} \mathrm{C}$ for $60 \mathrm{~s}, 60^{\circ} \mathrm{C}$ annealing temperature for $60 \mathrm{~s}, 72^{\circ} \mathrm{C}$ for $105 \mathrm{~s}$ (ND2: $120 \mathrm{~s}$ ), and a final extension of $72^{\circ} \mathrm{C}$ for $7 \mathrm{~min}$. Sequence reactions were visualized on a 3730 xl DNA Analyzer (Applied Biosystems, CA, USA).

\section{Phylogenetic analyses}

We aligned sequences using BioEdit [40] and by eye. Concordance of the two genes (ND2 and ND4) used to construct the dataset was evaluated using the partition-homogeneity test with the software PAUP* [41]. As these tests did not reveal significance incongruence between the two genes $(P=0.20)$, we conducted phylogenetic analyses on concatenated sequences (593 bp for $\mathcal{N} D 2+819$ bp for $\mathcal{N} D 4$ ); all codon positions were used. For the combined data set, sequences of species from the infraorder Scincomorpha were used to root the trees, as follows: one species of Cordylidae (Cordylus warreni, AB079613), one of Xantusiidae (Lepidophyma flavimaculatum, AB162908), two of Lacertidae (Lacerta viridis, AM176577; Takydromus takydromoides, AB080237), and one of Scincidae (Eumeces egregius, AB016606) from Albert et al. [42] and as in Dubey \& Shine [43]. All the nonBassiana species were used as outgroups.

For Maximum likelihood (ML) analyses, jModelTest 0.1.1 $[44,45]$ was used to select models of DNA substitution. The TrN+I+G model [46] best fitted the dataset using a Bayesian Information Criterion (BIC; [47] Schwarz 1978; Lset base $=\left(\begin{array}{llll}0.3559 & 0.3272 & 0.0877 & 0.2292\end{array}\right) \quad$ nst $=6 \quad$ rmat $=\left(\begin{array}{ll}1.0000\end{array}\right.$ $\begin{array}{lllll}13.9692 & 1.0000 & 1.0000 & 7.6755 & 1.0000)\end{array}$ rates = gamma shape $=0.4430$ pinvar $=0.1490)$. ML heuristic searches and bootstrap analyses (1000 replicates) were performed with phyml [44]. Bayesian analyses (BA) were conducted with the GTR model (nst =6), using MrBayes ver. 3.1.2.1 [48]. Two independent runs were performed, each consisting of four parallel Markov chain Monte Carlo (MCMC) chains of 3 million generations, allowing a good convergence of the independent runs (the average standard deviation of split frequencies being lower than 0.01). Trees were sampled every 100 generations. Burn-in was assessed by comparing the mean and variance of $\log$ likelihoods, both using the program Tracer ver. 1.4 [49] and by eye. Tree parameters reached stationarity after a burn-in period of 300,000 generations. Optimal trees were then sampled every 100 generations to obtain the final consensus BA tree and associated posterior probabilities.

Finally, we used Paup* 4.0b10 [40] to perform maximum parsimony (MP) analyses using 100 random additions of sequences followed by tree bisection and reconnection (TBR) branchswapping, and retaining at most 100 trees at each replicate. Branch support was estimated using 1000 bootstrap replicates with the same heuristic settings.

\section{Molecular dating}

We estimated divergence times with Beast 1.4 [50] using a coalescent tree prior (adequate to study intraspecific diversification: [51]. Because the fossil record for Australian skinks is limited [52], we used the combination of three different secondary calibration points from the study by Albert et al. [42] on the phylogeny of squamate reptiles based on two different molecular dating methods (BA: Bayesian, PL: penalized likelihood) and as in the recent study of Dubey \& Shine [43] on water skinks (see this 
study for details of methods and calibration points). Additional simulations were run with the same dataset and the same models, but strictly based on two different rates of divergence $(1.3 \%$ and $2.3 \% \mathrm{Myr}^{-1}$ ) derived from other reliable studies on reptiles [53$56]$.

Preliminary analyses were performed with an uncorrelated lognormal relaxed clock to test if a strict molecular clock can be rejected for our dataset (ucld.stdev parameter $>1$ with a frequency histogram not abutting 0). Because in our simulations (BA and PL based calibration, and the two divergence rates $1.3 \%$ and $2.3 \%$ $\mathrm{Myr}^{-1}$ ) the "ucld.stdev" parameters were all $<0.3$ with a frequency histogram abutting 0 , we chose a strict molecular clock for the analyses [51]. The analyses were performed with two independent chains and 20 million generations and chains were sampled every 1000 generations with a burn-in of 2 million generations.

\section{References}

1. Hewitt GM, Ibrahim KM (2001) Inferring glacial refugia and historical migrations with molecular phylogenies. In: Integrating Ecology and Evolution in a Spatial Context. BES Symposium Volume (Silvertown J, Antonovics J, Blackwells, eds.), pp. 271-294, Cambridge, UK: Cambridge University Press.

2. Markgraf V, McGlone M, Hope G (1995) Neogene paleoenvironmental and paleoclimatic change in southern temperate ecosystems - a southern perspective. Trends Ecol Evol 10: 143-147.

3. Kershaw AP, Martin HA, McEwen Mason JRC (1994) The Neogene - a period of transition. In: Hill RS, ed. Australian vegetation history. Cambridge: Cambridge University Press.

4. Melville J, Goebel S, Starr C, Keogh JS, Austin JJ (2007) Conservation genetics and species status of an endangered Australian dragon, Tympanocryptis pinguicolla (Reptilia: Agamidae). Conserv Genet 8: 185-195.

5. Byrne M, Yeates DK, Joseph L, Bowler J, Cooper S, et al. (2008) Birth of a biome: Synthesizing environmental and molecular studies of the assembly and maintenance of the Australian arid zone biota. Mol Ecol 17: 4398-4417.

6. Alley NF, Lindsay JM (1995) Tertiary. In: The Geology of South Australia (Drexel JF, Preiss WV, eds.), pp. 151-217, Adelaide, South Australia: South Australian Geological Survey, Bulletin 54.

7. McGowran B, Holdgate GR, Li Q, Gallagher SJ (2004) Cenozoic stratigraphic succession in southeastern Australia. Aust J Earth Sci 51: 459-496.

8. Martin HA (2006) Cenozoic climatic changes and the development of the arid vegetation of Australia. J Arid Environ 66: 533-563.

9. Bowler JM (1982) Aridity in the late Tertiary and Ouaternary of Australia. Evolution of the Flora and Fauna of Arid Australia (Barker WR, Greenslade PJM, eds.), pp. 35-45, Adelaide: Peacock Publications.

10. Frakes LA, McGowran B, Bowler JM (1987) Evolution of Australian environments. Fauna of Australia (Dyne GR, Walton DW, eds.), pp. 1-16, Canberra: Australian Government Publishing Service.

11. Gallagher SJ, Greenwood DR, Taylor D, Smith AJ, Wallace MW, et al. (2003) The Pliocene climatic and environmental evolution of southeastern Australia: evidence from the marine and terrestrial realm. Palaeogeogr Palaeocl 193: 349-382.

12. Sniderman JMK, Pillans B, O’Sullivan PB, Kershaw AP (2007) Climate and vegetation in southeastern Australia respond to Southern Hemisphere insolation forcing in the late Pliocene-early Pleistocene. Geology 35: 41-44.

13. Williams M, Dunkerley D, De Deckker P, Kershaw P, Chappell J (1998) Quaternary Environments, 2nd edn. London: Arnold.

14. Bowler JM, Kotsonis A, Lawrence CR (2006) Environmental evolution of the mallee region, Western Murray Basin. Proc Roy Soc Vict, 118: 161-210.

15. Schultz MB, Ierodiaconou DA, Smith SA, Horwitz P, Richardson AMM, et al. (2008) Sea-level changes and palaeo-ranges: reconstruction of ancient shorelines and river drainages and the phylogeography of the Australian land crayfish Engaeus sericatus Clark (Decapoda: Parastacidae). Mol Ecol 17: 5291-5314.

16. Williams MAJ (2000) Quaternary Australia: extremes in the last glacialinterglacial cycle. In: Billion-Year Earth History of Australia and Neighbours in Gondwanaland (Veevers JJ, ed.), pp. 55-59, Sydney, Australia: GEMOC Press.

17. Huey RB, Tewksbury JJ (2009) Can behavior douse the fire of climate warming? P Nat A Sci USA 106: 3647-3648.

18. Kearney MR, Porter W, Shine R (2009) The potential for behavioral thermoregulation to buffer 'cold-blooded' animals against climate warming. Proc Natl Acad Sci USA 106: 3835-3840.

19. Commonwealth of Australia (2005) Interim biogeographic regionalisation for Australia, version 6.1

20. Harris PT, Heap AD, Passlow V, Sbaffi L, Fellows M, et al. (2005) Geomorphic Features of the Continental Margin of Australia. Geoscience Australia Record 2003/30. Geoscience Australia, Canberra, Australia.

21. Keogh JS, Scott IAW, Hayes C (2005) Rapid and repeated origin of insular gigantism and dwarfism in Australian tiger snakes. Evolution 59: 226-233.

\section{Supporting Information}

Table S1 Species, location, collection code and Genbank accession numbers of samples (*see Albert et al. 2009 for details) Found at: doi:10.1371/journal.pone.0012982.s001 (0.15 MB DOC)

\section{Acknowledgments}

We thank Maya Chevalley and Scott Keogh for assistance and scientific advice, and the Museum Victoria, South Australian Museum, Australian National Wildlife Collection (CSIRO), Melanie Elphick, David Pike, and Ben Croak for tissue samples.

\section{Author Contributions}

Conceived and designed the experiments: SD RS. Performed the experiments: SD. Analyzed the data: SD. Wrote the paper: SD RS.

22. Oliver P, Hugall A, Adams M, Cooper SJB, Hutchinson M (2007) Genetic elucidation of cryptic and ancient diversity in a group of Australian diplodactyline geckos: the Diplodactylus vittatus complex. Mol Phylogenet Evol 44: 77-88.

23. Fairbairn J, Shine R, Moritz C, Frommer M (1998) Phylogenetic Relationships between Oviparous and Viviparous Populations of an Australian Lizard (Lerista bougainvillii, Scincidae). Mol Phylogenet Evol 10: 95-103.

24. Symula R, Keogh JS, Cannatella D (2008) Ancient phylogeographic divergence in southeastern Australia among populations of the widespread common froglet, Crinia signifera. Mol Phylogenet Evol 47: 569-580.

25. Schaüble CS, Moritz C (2001) Comparative phylogeography of two open forest frogs from eastern Australia. Biol J Linn Soc 74: 157-170.

26. Chapple DG, Keogh JS, Hutchinson MN (2005) Substantial genetic substructuring in southeastern and alpine Australia revealed by molecular phylogeography of the Egernia whitii (Lacertilia: Scincidae) species group. Mol Ecol 14: 1279-1292.

27. Donnellan SC, McGuigan K, Knowles R, Mahony M, Moritz C (1999) Genetic evidence for species boundaries in frogs of the Litoria citropa species-group (Anura: Hylidae). Aust J Zool 47: 275-293.

28. Colgan DJ, O'Meally D, Sadlier RA (2009) Phylogeographic patterns in reptiles on the New England Tablelands at the south-western boundary of the McPherson Macleav Overlap. Aust J Zool 57: 317-328.

29. Taberlet P, Fumagalli L, Wust-Saucy AG, Cosson JF (1998) Comparative phylogeography and postglacial colonization routes in Europe. Mol Ecol 7: 453-464.

30. Hewitt GM (1999) Post-glacial re-colonization of European biota. Biol J Linn Soc 68: 87-112.

31. Hewitt GM (2004) The structure of biodiversity - insights from molecular phylogeography. Front Zool 1: 4.

32. Emerson BC, Hewitt GM (2005) Phylogeography. Curr Biol 15: R367-R371.

33. Dubey S, Shine R (2010) Geographic variation in the age of temperate-zone reptile and amphibian species: southern Hemisphere species are older. Biol Lett. DOI: $10.1098 / \mathrm{rsbl} .2010 .0557$.

34. Smith MA (1937) A review of the genus Lygosoma (Scincidae: Reptilia) and its allies. Rec Indian Mus 39: 213-234.

35. Cogger HG (1983) Reptiles and Amphibians of Australia. Sydney: Reed Books.

36. Wells RW, Wellington CR (1984) A synopsis of the class Reptilia in Australia. Aust J Herpetol 1: 73-129.

37. Cogger HG (2000) Reptiles and Amphibians of Australia. Sydney: Reed Books.

38. Arevalo E, Davis SK, Sites JW (1994) Mitochondrial sequence divergene and pohylogenetic among eight chromosome races of the Sceloporus grammicus complex (Phrynosomatidae) in central Mexico. Syst Biol 43: 387-418.

39. Read K, Keogh JS, Scott IAW, Roberts JD, Doughty P (2001) Molecular phylogeny of the Australian frog genera Crinia, Geocrinia, and allied taxa (Anura: Myobatrachidae). Mol Phylogenet Evol 21: 294-308.

40. Hall TA (1999) BioEdit: a user-friendly biological sequence alignment editor and analysis program for Windows 95/98/NT. Nucleic Acids Symp Ser 41: 95-98.

41. Swofford DL (2001) PAUP*. Phylogenetic Analysis Using Parsimony (* and other Methods). Version 4.0b1. Sinauer Associates, Sunderland, MA, USA.

42. Albert EM, Mauro DS, Garcia-Paris M, Rüber L, Zardoya R (2009) Effect of taxon sampling on recovering the phylogeny of squamate reptiles based on complete mitochondrial genome and nuclear gene sequence data. Gene 441: $12-21$.

43. Dubey S, Shine R (2010) Pleistocene diversification and genetic population structure of an endangered lizard (the Blue Mountains water skink, Eulamprus leuraensis) in southeastern Australia. J Biogeogr 37: 902-914.

44. Guindon S, Gascuel O (2003) A simple, fast, and accurate algorithm to estimate large phylogenies by maximum likelihood. Syst Biol 52: 692-704.

45. Posada D (2008) jModelTest: phylogenetic model averaging. Mol Biol Evol 25: $1253-1256$. 
46. Tamura K, Nei M (1993) Estimation of the number of nucleotide substitutions in the control region of mitochondrial DNA in humans and chimpanzees. Mol Biol Evol 10: 512-526.

47. Schwarz G (1978) Estimating the dimension of a model. Ann Statist 6: 461-464.

48. Huelsenbeck JP, Ronquist F, Nielsen R, Bollback JP (2001) Evolution: Bayesian inference of phylogeny and its impact on evolutionary biology. Science 294: 2310-2314.

49. Rambaut A, Drummond A (2007) Tracer v1.4. Available from http://beast.bio. ed. ac.uk/Tracer.

50. Drummond AJ, Rambaut A (2006) BEAST v1.4. Available at: http://beast.bio. ed.ac.uk/.

51. Drummond AJ, Ho SYW, Rawlence N, Rambaut A (2007) A Rough Guide to BEAST 1.4. Available at: http://beast.bio.ed.ac.uk/.
52. Martin JE, Hutchinson MN, Meredith R, Case JA, PledgeL NS (2004) The oldest genus of Scincid Lizard (Squamata) from the Tertiary Etadunna Formation of South Australia. J Herpetol 38: 180-187.

53. Zamudio KR, Greene HW (1997) Phylogeography of the bushmaster (Lachesis muta: Viperidae): implications for Neotropical biogeography, systematics, and conservation. Biol J Linn Soc 62: 421-442.

54. Macey JR, Schulte JA, Larson A, Tuniyev BS, Orlov N, et al. (1999) Molecular phylogenetics, tRNA evolution, and historical biogeography in anguid lizards and related taxonomic families. Mol Phylogenet Evol 12: 250-272.

55. Brown RP, Terrasa B, Pérez-Mellado V, Castro JA, Hoskisson PA, et al. (2008) Bayesian estimation of post-Messinian divergence times in Balearic Island lizards. Mol Phylogenet Evol 48: 350-358.

56. Torres-Carvajal O, de Queiroz K (2009) Phylogeny of hoplocercine lizards (Squamata: Iguania) with estimates of relative divergence times. Mol Phylogenet Evol 50: 31-43. 